УДК 639

\title{
МЕТОДИЧЕСКИЕ РЕКОМЕНДАЦИИ ДЛЯ НАПИСАНИЯ ВЫПУСКНЫХ КВАЛИФИКАЦИОННЫХ РАБОТ ПО ИХ НАЗВАНИЮ (НАПРАВЛЕНИЕ ПОДГОТОВКИ 35.03.08 «ВОДНЫЕ БИОРЕСУРСЫ И АКВАКУЛЬТУРА»)
}

Гринберг Екатерина Владимировна старший преподаватель ФГБОУ ВО «Сахалинский государственный университет» Институт морской геологии и геофизики ДВО РАН

Литвиненко Анна Владимировна к.б.н., доцент ФГБОУ ВО «Сахалинский государственный университет»

Аннотация. В методических рекомендациях в простой и доступной форме пояснено, как выпускникам направления подготовки 35.03.08 «Водные биоресурсы и аквакультура», профиль «Аквакультура» (бакалавриат) составить план исследования по его названию и написать выпускную квалификационную работу. Подробно описано наполнение каждого обязательного раздела исследовательской работы, её примерное содержание, перечислены документы и материалы, к которым необходимо обратиться непосредственно на предприятии, на базе которого проводилось исследование. Рекомендации, изложенные в данном методическом руководстве, в равной степени помогут написать как курсовую работу, так и составить отчет о прохождении производственной практики.

Ключевые слова: выпускная квалификационная работа, аквакультура, водные биоресурсы, лососевый рыбоводный завод, искусственное разведение, тихоокеанские лососи.

\section{METHODOLOGICAL RECOMMENDATIONS FOR WRITING GRADUATE QUALIFICATION WORKS BY THEIR TITLE (DIRECTION OF TRAINING 35.03.08 "WATER BIORESOURCES AND AQUACULTURE")}

Grinberg Ekaterina Vladimirovna Litvinenko Anna Vladimirovna 
Abstract. The guidelines explain in a simple and accessible form how graduates of the training area 35.03.08 "Water bioresources and aquaculture", the profile "Aquaculture " (bacalaureate) should make a research plan based on its name and write a final qualifying work. The publication describes in detail the content of each mandatory section of the research work, its approximate content, lists documents and materials that need to be accessed directly at the enterprise on the basis of which the research was conducted.

Keywords: final qualification work, aquaculture, aquatic biological resources, salmon hatchery, artificial breeding, Pacific salmon.

Опираясь на изначальное название выпускной квалификационной работы (ВКР), составляют план исследования, выделяют и называют основные разделы, формулируют цель и задачи. Важно использовать в названии разделов и подразделов, при составлении плана работы, каждое слово или словосочетание из названия работы. Кроме того, помимо слов и словосочетаний из названия работы, в её содержании должна присутствовать дополнительная информация, которая позволит раскрыть тему полностью.

Большинство выпускных работ по специальности 35.03 .08 «Водные биоресурсы и аквакультура» посвящены биотехнике искусственного разведения тихоокеанских лососей в условиях конкретного рыбоводного завода (ЛРЗ). По этой причине литературный обзор для большинства ВКР будет схожим, а практическая часть - различаться.

В качестве примера алгоритма составления плана работы и написания ВКР, приведем следующее название: «Особенности кормления молоди кеты в условиях Охотского лососевого рыбоводного завода». Напоминаем, что в содержании работы необходимо отразить все слова или словосочетания из ее названия.

Любая ВКР обучающегося состоит из семи основных частей и разделов: титульный лист, содержание, введение, литературный обзор, практическая часть, заключение и список цитируемых источников [1]. Дополнительно в работе оформляют Приложения.

Титульный лист. Помимо названия работы и фамилии её автора, титульный лист содержит полное название учебного заведения обучающегося, фамилию, должность и звание научного руководителя, а также место и год защиты ВКР.

Содержание. Примерное содержание ВКР с названием «Особенности кормления молоди кеты в условиях Охотского ЛРЗ» представлено в таблице 1. 
Таблица 1

Примерное содержание ВКР на тему: «Особенности кормления молоди кеты в условиях Охотского лососевого рыбоводного завода»

\begin{tabular}{|c|l|c|}
\hline$№$ п/п & \multicolumn{1}{|c|}{ Название разделов/подразделов } & Стр. \\
\hline & Введение & 3 \\
\hline 1 & История и технологическая карта Охотского ЛР3 & \\
\hline 2 & Биология кеты (Oncorhynchus keta) & $\begin{array}{l}2.1 \text { Особенности личиночного и малькового этапов развития } \\
\text { тихоокеанских лососей }\end{array}$ \\
\hline 3 & $\begin{array}{l}\text { Биотехника искусственного разведения тихоокеанских } \\
\text { лососей }\end{array}$ & \\
\hline & $\begin{array}{l}\text { 3.1 Особенности этапа подращивания молоди тихоокеанских } \\
\text { лососей в искусственных условиях }\end{array}$ & \\
\hline 4 & Материалы и методики & \\
\hline 5 & Обсуждение результатов работы. Выводы & \\
\hline & Заключение & \\
\hline & Список цитируемой литературы & \\
\hline
\end{tabular}

Введение. Во введении к работе излагают её актуальность: о масштабах развития рыбохозяйственной отрасли в целом по стране и в Сахалинской области, об объемах добычи лососевых по Дальневосточному и отдельно Сахалино-Курильскому региону, о конкретном вкладе в общий объем вылова от деятельности Охотского ЛРЗ; о важности и причинах развития искусственного рыборазведения; об успехах и достижениях сахалинских и курильских рыбоводов; о конкретных показателях закладки икры в предыдущие годы, выпуска молоди и промысловом возврате (в штуках, тоннах, процентах) на Охотский лососевый рыбоводный завод (Охотский ЛРЗ), а также раскрывают проблематику, связанную с конкретной темой исследования, например, о важности этапа кормления молоди в искусственном разведении.

Далее во введении, исходя из актуальности и названия работы, формулируют цель. Цель работы должна быть едина, конечна и решаема. Формулировку цели работы начинают с таких слов (глаголов) или словосочетаний как «дать оценку», «оценить», «выяснить», «определить», «сравнить». Нежелательно использовать глаголы «рассмотреть», «изучить», «ознакомиться». 
Для достижения цели работы необходимо сформулировать и решить несколько задач. Обычно эти задачи совпадают с названиями основных разделов или подразделов работы и численно совпадают с ними. Иногда количество разделов работы может быть на 1-2 больше количества задач.

Задачи формулируют, начиная со слов «изучить/изучили», «выяснить/выяснили», «оценить/оценили», «сравнить/сравнили» и т. д. Для написания ВКР вполне достаточно решить от трех-четырех до пяти-шести задач.

Далее формулируют объект и предмет исследования. В работе с выше предложенным названием, объект исследования - это молодь кеты, а предмет исследования - особенности ее кормления.

После того как выделен объект и предмет исследования, необходимо выяснить, в чем состоит научная новизна работы и ее практическая значимость. Научная новизна (окончательно ее определяют и формулируют тогда, когда работа будет готова на 95\% и более) может состоять в том, что до настоящего исследования этим вопросом никто не интересовался или не изучал. Возможно, по данному вопросу очень много исследований, но один из аспектов изучен недостаточно или вообще не изучен (например, специфические особенности отдельного этапа биотехники на конкретном ЛР3).

Практическую значимость формулируют исходя из научной новизны и того, как проведено и проанализировано исследование, сделаны выводы и сформулировано заключение. Практическая значимость показывает, как результаты проведенного исследования помогут на практике, в реальных условиях конкретного ЛРЗ и отразятся на эффективности его работы.

Завершить введение необходимо благодарностями обучающегося специалистам предприятия, где он проходил производственную практику, преподавателям, персоналу учебного заведения, научному руководителю и всем, кого автор считает нужным поблагодарить.

Литературный обзор или обзор литературных источников. Литературный обзор - это теоретическая часть работы, в которой обучающийся демонстрирует, насколько хорошо он проработал литературу по теме своего исследования. В процессе написания ВКР необходимо проработать не менее 20-25 литературных источников, из них не менее 1820 источников должны составлять не открытые интернет-источники, а книги и статьи. Как правило, в итоговых вариантах работ по профилю «Аквакультура», количество цитируемых источников не менее 30-35. 
В этой главе приводят сведения из литературных источников об особенностях физико-географического расположения района исследований; биологии объекта исследования; особенностях определенных этапов развития объекта исследования; биотехнике проведения производственного периода/этапа на рыбоводных предприятиях и т.д.

Для написания ВКР с вышеуказанным названием, необходимо собрать и изучить материалы по: истории и характеристике Охотского ЛРЗ; биологии кеты; особенностям личиночного и малькового этапов развития; биотехнике искусственного разведения тихоокеанских лососей; особенностям этапа кормления молоди тихоокеанских лососей с коротким пресноводным циклом.

На основании этих же сведений формулируют и основные задачи работы, начиная их с глаголов, например: выяснить биотехнику искусственного разведения тихоокеанских лососей; определить особенности малькового этапа развития лососей и т. д.

Следующая часть работы - практическая. Здесь приводят собранные материалы и данные; перечисляют примененные в процессе прохождения производственной практики и при сборе материалов для написания работы методики; анализируют; сравнивают; делают выводы и заключения; формулируют предложения для улучшения работы предприятия. В этой же части необходимо размещать фото, таблицы и графики.

Материалы и методики. В подразделе перечисляют методики (со ссылкой на литературные источники), которые были применены в ходе исследования, описывают и перечисляют оборудование для проведения измерений и проведения работ по исследованию, а собранный цифровой материал группируют в таблицы, здесь же уместно разместить фото (цехов и участков, инструментов и оборудования, процесса проведения биологических анализов, измерений, обнаруженных паразитов и т. д.).

В подразделе Обсуждение результатов работы, обучающиеся анализируют собранные материалы, сравнивают их и делают выводы. В этом же подразделе уместно разместить замечания и предложения для увеличения эффективности работы конкретного предприятия, если таковые имеются.

Заключение. Заключение - это завершающая часть работы, которую несложно написать, если работа в целом завершена; краткое изложение результатов работы, резюмирующее ее содержание и свидетельствующее о том, что поставленные задачи выполнены, а цель работы достигнута. Поэтому, писать заключение рекомендуем по задачам из введения ВКР, формулируя изложенный в каждом разделе материал в двух-трех 
предложениях. Акцент в заключении необходимо сделать на результатах практической части работы. Таким образом, количество абзацев в заключении должно быть примерно равно количеству поставленных задач или на несколько больше.

Например, если была поставлена задача «изучить физико-географическое расположение Охотского ЛРЗ», то в заключении соответствующий абзац может быть изложен так: «Охотский ЛРЗ расположен в Корсаковском районе в ... км от населенного пункта Охотское. Базовый водоток - p. Ударница, впадающая в озеро Тунайча, которое соединяется с заливом Мордвинова Охотского моря узкой протокой Красноармейская».

Завершается написание работы подробным списком использованных источников (оформленным согласно ГОСТ [2]), ссылки на которые необходимо делать по всему тексту исследования.

Приложение или приложения к работе размещают после списка цитируемых источников. В приложение, как правило, выносят собранные статистические материалы, оформленные в виде таблиц, а также фото.

ВКР оформляют в соответствии с требованиями нормоконтроля, принятыми в учебном заведении и с Положением о ВКР. В этом же Положении указан примерный объем работы в страницах, процентное соотношение различных частей работы, количество литературных источников для цитирования, регламент предзащиты и защиты ВКР и многое другое.

Список сведений и материалов, которые необходимо собрать при прохождении производственной практики для подготовки и написания отчета, курсовой работы (КР) или ВКР очень обширен, но именно полнота собранных сведений и данных, позволит их проанализировать и написать достойную исследовательскую работу, а также защитить её на «хорошо» или «отлично».

Сведения, данные и материалы, которые необходимо собрать для исследования (отчет, КР, ВКР), сгруппированы нами по примерным задачам, поставленным для достижения цели исследования.

Характеристика предприятия. Год образования, полное официальное название, статус, подчиненность, количество работников, количество отделов или подразделений (структура), основной и дополнительные виды деятельности, оснащение и т. д. Если предприятие - рыбоводный завод, нерестово-выростное хозяйство или товарное хозяйство, то необходимо выяснить его мощность (по выпуску молоди, товарной рыбы, по закладке икры), какие виды или породы рыб разводят и выращивают (количество и соотношение в долях, если несколько видов или пород), какое оборудование 
используют для отлова и выдерживания производителей, инкубации икры, выдерживания предличинок, подращивания личинок и мальков, выращивания товарной рыбы, краткий календарный план работы предприятия, источники водоснабжения и объем водопотребления (общий и по этапам технологического процесса), выяснить эпизоотическую обстановку, знать характеристику базового водоема или водотока предприятия и др.

Биология вида. Характеристика породы. Необходимо кратко привести только основные сведения: размеры, масса, жизненный цикл, ареал, возраст полового созревания, плодовитость, возрастная, половая, пространственная и временная (сроки и продолжительность нерестового хода) структуры популяции, характер кормовых и нерестовых миграций, тип питания, внутривидовые и внутрипопуляционные дифференциации (при наличии), половой диморфизм, наличие/отсутствие и характер/особенности брачного наряда, принадлежность к той или иной экологической группе. Одомашнен или нет вид, особенности и достоинства породы.

Биотехника искусственного разведения. Кратко привести технологическую цепочку «от икринки до малька» или «от икринки до товарной рыбы». Обозначить специфические особенности каждого этапа/звена с точки зрения биотехники рыбоводства и специфики этапа развития рыб. Привести перечень необходимых для выращивания рыбы цехов и оборудования, инструментария. Обозначить тип, систему/цикл и оборотность предприятия (тепловодное или холодноводное, полносистемное или неполносистемное, полноцикловое или неполноцикловое, одно-, двухили трехлетний оборот выращивания продукции).

Отдельные этапы биотехники. Для характеристики рыбоводного цикла в целом, для любого его этапа, необходимо собрать следующие материалы и сведения: средняя температура воды (подекадно), ${ }^{\circ} \mathrm{C}$; содержание растворенного в воде кислорода (подекадно), мг/л; температура воздуха (подекадно), ${ }^{\circ} \mathrm{C}$; расход воды (на один канал/бассейн, на один миллион штук продукции, на один килограмм продукции, общий расход), л/с; плотность

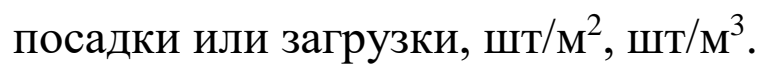

На этапе работы с производителями собирают следующие сведения. Ежедневные температура воды и содержание кислорода в море/устье, в зоне отстоя производителей перед рыбозаграждением пункта сбора икры, в преднерестовом бассейне/пруду; сроки и динамика численности нерестового хода (начало, середина, пик/массовый, окончание хода); графики пропуска на естественные нерестилища; результаты биологических анализов 
производителей с указанием степени зрелости их гонад; характеристика условий выдерживания производителей (высота воды, плотность посадки, расход); продолжительность выдерживания и отход за период выдерживания; количество рыб, использованных для рыборазведения, пропущенных на естественные нерестилища, изъятых промыслом (излишних); возрастная структура стада в текущем году и в предыдущие годы; промысловый возврат в штуках, тоннах, процентах за последние три, пять, семь и более лет.

Если имеются сведения о результатах массового маркирования рыбоводной продукции с ЛРЗ, то можно привести данные о происхождении использованных производителей.

Этап сбора икры, подготовки ее к инкубации и транспортировка. Количество самок, использованных для сбора икры в одну емкость (таз), количество самцов для осеменения этой икры, способ осеменения. Продолжительность процесса оплодотворения, промывки икры. Методика промывки икры. Количество самок, от которых закладывают икру для набухания в один контейнер или емкость для набухания. Продолжительность сбора икры в одну емкость или контейнер. Температура и качество воды для осеменения, промывки и набухания икры. Продолжительность набухания икры. Способ и методика упаковывания и транспортировки икры в контейнерах. Расстояние для транспортировки (от пункта сбора икры до инкубационного цеха). Вид транспорта, скорость транспортировки.

Инкубация. Время от окончания набухания икры, сливания воды и упаковки контейнеров с икрой, до доставки их в инкубационный цех. Способ выравнивания температуры икры и воды в инкубаторе. Способ и методика учета икры. Методика раскладывания («загрузки») икры в инкубаторы. Название и принцип работы инкубационных аппаратов. Количество икры в одном транспортировочном контейнере, в одном инкубационном аппарате или его отсеке (плотность загрузки).

Проводят или нет на предприятии профилактические обработки икры в период инкубации (периодичность, название антисептика/антисептиков, экспозиция и концентрация). Соблюдение ветеринарно-санитарных правил в инкубационном цеху. Температура воды и ее гидрохимическая характеристика (содержание кислорода, $\mathrm{pH}$, грунтовая/поверхностная), расход воды на один аппарат и в целом. Изменяются ли регистрируемые параметры среды в процессе инкубации. Соблюдают ли на предприятии световой режим инкубации или, наоборот, режим затемнения. 
Изменение диаметра и массы икринок в процессе инкубации (у лососей: при закладке икры, на стадии пигментации глаз и перед вылуплением). Возраст (дата, градусодни и календарные дни) наступления ключевых стадий развития («глазок», начало и окончание вылупления, массовое вылупление). Продолжительность периода инкубации. Отход (в абсолютном и относительном выражении) за период инкубации с указанием его составляющих частей (производственный отход при его выборке, отход перед выносом икры для вылупления и отход после вылупления свободных эмбрионов).

Если в процессе инкубации икры было проведено сухое мечение отолитов, то описать методику проведения мечения, температуру воды в дни мечения и код сформированной метки.

Выдерживание предличинок. Морфометрическая характеристика каждой партии в период массового вылупления и данные биологических анализов по старшим (первым), средним и младшим (последним) контрольным партиям в конце каждого календарного месяца периода выдерживания. На этапе подъема на плав и начала кормления молоди, необходимы данные анализов всех партий.

Возраст наступления стадии массового вылупления, подъема личинок на плав и начала кормления (дата, градусодни и календарные дни). Продолжительность периода выдерживания. Общий и суточный линейный прирост, прирост массы тела и резорбция желточного мешка, оправданность резорбции (\%).

Эпизоотическая обстановка на предприятии и ихтиопатологическое состояние молоди рыб. Условия абиотики и биотики (температура воды, содержание растворенного в воде кислорода и углекислоты, $\mathrm{pH}$, плотность посадки, высота воды, размеры питомных каналов, лотков или бассейнов, наличие субстрата для выдерживания и его характеристика и т.д.).

Если в период выдерживания предличинок было проведено термомечение отолитов, то необходимо описать методику проведения мечения, температуру воды в дни мечения, градиент температур и код сформированной метки.

Величина производственного отхода, контроль качества предличинок, наличие аномалий развития, уродств.

Подращивание личинок и мальков. Название, состав и способ изготовления искусственного корма или кормов для раскармливания личинок и кормления мальков. Культивируют или нет на предприятии живые корма. 
Указать виды культивируемых объектов. Характеристика кормов (сбалансированность, полноценность, коэффициент оплаты корма/кормовой коэффициент).

Ручной или механический способ раздачи кормов. Тип, емкость, загрузка кормушек. Интервал, кратность, продолжительность одного кормления и кормлений. Суточный рацион (пример таблиц для расчета суточного рациона).

Абиотические условия при кормлении: температура воды, $\mathrm{pH}$, газовый режим, соленость, освещенность, фотопериодизм, высота воды при подращивании, расход воды (на один канал или бассейн, на один миллион продукции, на всю продукцию) и т. д. Биотические условия: плотность

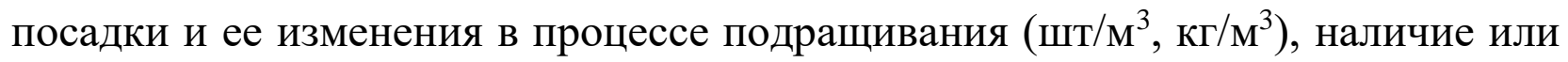
отсутствие естественной кормовой базы, ихтиопатологическое и физиологическое состояние продукции, эпизоотическая обстановка в зоне расположения предприятия и т. д.

Результаты биологических анализов контрольных партий и групп кормления. Частота проведения контрольных взвешиваний и корректировки суточного рациона. Методика проведения биоанализа (прижизненно или посмертно). Общий и суточный линейный и весовой приросты. Оправданность кормовых затрат.

Динамика доли питающихся рыб при переводе на внешнее питание. За сколько суток $100 \%$ личинок переходят на питание искусственным кормом. Величина производственного отхода за период подращивания.

Выпуск молоди. Указать в каком возрасте выпускают продукцию (сеголетки, подращённые сеголетки, годовики, двух- или трехлетки). Количество выпущенных рыб, длина по АС и по АД, масса, коэффициент упитанности по Фультону. Сроки и продолжительность выпуска, время суток, количество рыб в каждом выпуске, количество выпусков. Длина миграционного пути.

Вариационные ряды по каждому выпуску отдельно и в целом, с построением графиков и анализом соответствия полученных кривых нормальной.

Экологические (абиотические и биотические) условия в предустьевой зоне базового водотока в период естественного ската и выпуска молоди.

Большинство вышеприведенных данных и сведений можно собрать из первичной и текущей рыбоводной документации, а также из различных планов, графиков и моделей, формируемых на ЛРЗ. В таблице 2 перечислены 
основные журналы, которые обязательно находятся на любом ЛРЗ и их ежедневно или ежедекадно заполняют специалисты-рыбоводы.

Таблица 2

Перечень журналов первичной рыбоводной отчетности ЛР3 и их примерное содержание

\begin{tabular}{|c|c|c|}
\hline $\begin{array}{l}\text { № } \\
\Pi / \Pi\end{array}$ & Название журнала & Примерное содержание, вносимые сведения \\
\hline 1 & Гидрометеонаблюдений & $\begin{array}{l}\text { Температура воды водоводов, на } \\
\text { производственных участках; температура } \\
\text { воздуха; расход воды отдельно по } \\
\text { участкам; содержание кислорода; состояние } \\
\text { погоды; высота снежного покрова }\end{array}$ \\
\hline 2 & $\begin{array}{l}\text { Учета градусодней } \\
\text { (возраста) }\end{array}$ & $\begin{array}{l}\text { Первое перемешивание икры; «глазок»; } \\
\text { «стресс»; выборка; вынос на вылупление; } \\
\text { начало, массовое и окончание вылупления; } \\
\text { начало кормления; выпуск }\end{array}$ \\
\hline 3 & $\begin{array}{l}\text { Учета рыбоводной } \\
\text { продукции }\end{array}$ & $\begin{array}{l}\text { Количество собранной и заложенной икры; } \\
\text { «процент оплодотворения»; количество } \\
\text { икры по итогам инвентаризации; отход за } \\
\text { период инкубации, выдерживания и } \\
\text { подращивания; дата и возраст наступления } \\
\text { стадий «глазка», массового вылупления, } \\
\text { начала кормления и выпуска; масса общая, } \\
\text { масса желточного мешка и запас } \\
\text { желточного мешка при переводе личинок } \\
\text { на внешнее питание; масса мальков при } \\
\text { выпуске }\end{array}$ \\
\hline 4 & $\begin{array}{l}\text { Учета лечебно- } \\
\text { профилактических } \\
\text { мероприятий }\end{array}$ & $\begin{array}{l}\text { Номер обрабатываемых партий, номер } \\
\text { инкубационного аппарата или } \\
\text { канала/бассейна/пруда; стадия развития } \\
\text { продукции; название антисептика; } \\
\text { концентрация и экспозиция антисептика; } \\
\text { количество антисептика; причина } \\
\text { обработки; ответственный за обработку }\end{array}$ \\
\hline
\end{tabular}




\begin{tabular}{|c|c|c|}
\hline $\begin{array}{c}\text { № } \\
\Pi / \Pi\end{array}$ & Название журнала & Примерное содержание, вносимые сведения \\
\hline 5 & Промысловый & $\begin{array}{l}\text { Ежедневный вылов в кг или в тоннах до } \\
\text { тысячных }(0,000) ; \text { вылов по нарастающей }\end{array}$ \\
\hline 6 & $\begin{array}{l}\text { Динамики хода } \\
\text { производителей }\end{array}$ & $\begin{array}{l}\text { Ежедневный пропуск или вылов в штуках; } \\
\text { пропуск по нарастающей }\end{array}$ \\
\hline 7 & $\begin{array}{l}\text { Биологических анализов } \\
\text { производителей }\end{array}$ & $\begin{array}{l}\text { Длины АС и АД; масса общая; масса самок } \\
\text { без яичников; масса яичников; АИП }\end{array}$ \\
\hline 8 & $\begin{array}{l}\text { Биологических анализов } \\
\text { икры, предличинок, } \\
\text { личинок и мальков }\end{array}$ & $\begin{array}{l}\text { Икра: диаметр и масса; предличинки и } \\
\text { личинки: длины АС и АД, масса общая и } \\
\text { масса желточного мешка; мальки: длины } \\
\text { АС и АД, масса }\end{array}$ \\
\hline 9 & $\begin{array}{l}\text { Первичного учета } \\
\text { собранной и } \\
\text { заложенной икры }\end{array}$ & $\begin{array}{l}\text { Масса собранной икры с тарой, масса тары, } \\
\text { масса икры; масса пробы, количество } \\
\text { икринок в пробе, масса одной икринки; } \\
\text { количество икры в партии; количество и } \\
\text { номер заполненных партией } \\
\text { инкубационных аппаратов }\end{array}$ \\
\hline 10 & Учета водопотребления & $\begin{array}{l}\text { Ежедневный расход воды по водоводам; } \\
\text { ежедневный расход по производственным } \\
\text { участкам; }\end{array}$ \\
\hline 11 & $\begin{array}{l}\text { Ихтиопатологических } \\
\text { исследований }\end{array}$ & $\begin{array}{l}\text { Количество исследованных личинок и } \\
\text { мальков; номер партии и канала; } \\
\text { температура воды; название обнаруженного } \\
\text { эктопаразита; экстенсивность и } \\
\text { интенсивность носительства }\end{array}$ \\
\hline 12 & $\begin{array}{l}\text { Учета } \\
\text { производственного } \\
\text { отхода (ведомости } \\
\text { выборки отхода) }\end{array}$ & $\begin{array}{l}\text { Номер выбранной партии; количество } \\
\text { выбранного отхода; количество оставшейся } \\
\text { продукции }\end{array}$ \\
\hline
\end{tabular}

Список текущей и отчетной рыбоводной документации и других источников на ЛР3, для написания отчетов о прохождении производственной практики, КР и ВКР:

- информации о производственно-хозяйственной деятельности предприятия (ежемесячные); 
- отчеты о производственно-хозяйственной деятельности предприятия за I и П полугодия (например, для характеристики рыбоводного цикла 2018-2019 гг. необходимо попросить на предприятии отчет за П полугодие 2018 года и отчет за І полугодие 2019 года);

- отчет о количестве выловленных и использованных производителей;

- акт сбора икры;

- акт инвентаризации икры;

- акт выпуска молоди с приложениями;

- график пропуска производителей на естественные нерестилища;

- график сбора икры;

- график терморегуляции;

- график подъема молоди на плав и начала кормления;

- график выпуска молоди.

Таким образом, название исследовательской студенческой работы служит основой для составления плана, содержания и написания КР или ВКР.

\section{Список литературы}

1. Выпускная квалификационная работа бакалавра https://edunews.ru/students/vypusknaya/trebovaniya-k-strukture-obemusoderzhaniyu-chastej-vkr-bakalavra.html (дата обращения 12.12.2020)

2. ГОСТ Р 7.0.5-2008 «Библиографическая ссылка». Термины и определения.

(C) Е.В. Гринберг, А.В. Литвиненко, 2020 